Portland State University

PDXScholar

Environmental Science and Management

Faculty Publications and Presentations

\title{
Integrating Liana Abundance and Forest Stature into an Estimate of Total Aboveground Biomass for an Eastern Amazonian Forest
}

Jeffrey J. Gerwing

Pennsylvania State University - Main Campus

Damiao Lopes Farias

Institute of People and the Environment in Amazonia

Follow this and additional works at: https://pdxscholar.library.pdx.edu/esm_fac

Part of the Forest Biology Commons

Let us know how access to this document benefits you.

\begin{abstract}
Citation Details
Jeffrey John Gerwing and Damião Lopes Farias (2000). Integrating liana abundance and forest stature into an estimate of total aboveground biomass for an eastern Amazonian forest. Journal of Tropical Ecology, 16, pp 327-335
\end{abstract}

This Article is brought to you for free and open access. It has been accepted for inclusion in Environmental Science and Management Faculty Publications and Presentations by an authorized administrator of PDXScholar. Please contact us if we can make this document more accessible: pdxscholar@pdx.edu. 


\title{
Integrating liana abundance and forest stature into an estimate of total aboveground biomass for an eastern Amazonian forest
}

\author{
JEFFREY JOHN GERWING ${ }^{1 *} \S$ and DAMIÃO LOPES FARIAS* \\ *Institute of People and the Environment in Amazonia (IMAZON), Caixa Postal 5101, \\ Belém-Pará, 66613-970, Brazil \\ \$Interdepartmental Program in Ecology, Pennsylvania State University, State College, PA \\ 16802, USA \\ (Accepted 5th October 1999)
}

\begin{abstract}
This study provides an estimate of aboveground live biomass for an intact eastern Amazonian forest. An allometric regression biomass equation was developed to estimate the aboveground biomass of live lianas. This equation, together with a previously published equation for trees, was then used to estimate the contributions of lianas and trees to the total biomass of forest patches in four stature classes: gap (openings in the canopy of at least $25 \mathrm{~m}^{2}$ with the dominant vegetation $<3 \mathrm{~m}$ high), low (3-15 m canopy height), medium (15-25 m canopy height), and high (>25 m canopy height). Total stand-level biomass was estimated as the weighted average of the stature classes. In 130 ha of surveyed forest, forest stature classes were found in the following proportions: gap phase 8\%; low stature $31 \%$; medium stature $44 \%$; and high stature $17 \%$. Total aboveground biomass was found to be three times higher in high stature forest than in low. Liana biomass, however, showed the opposite result, being three times higher in low stature forest. Stand-level aboveground live biomass was estimated at $314 \mathrm{t} \mathrm{ha}^{-1}$ of which $43 \mathrm{t}$ $\mathrm{ha}^{-1}(14 \%)$ was lianas. Liana leaf area index (LAI) ranged from $1.3 \mathrm{~m} \mathrm{~m}^{-2}$ in high stature forest to $5.3 \mathrm{~m} \mathrm{~m}^{-2}$ in low stature. Abundant lianas are generally interpreted as a sign of past forest disturbance. As forests throughout the Amazon basin are increasingly disturbed through human activities, it is likely that their biomass will be underestimated if the contribution of lianas is ignored.
\end{abstract}

KEY WORDS: aboveground biomass, Amazon, leaf area index, liana, tropical forest, allometry

\section{INTRODUGTION}

Even relatively small changes in the carbon balance of Amazonian rain forests could greatly impact both the global carbon balance and global climate change

${ }^{1}$ To whom correspondence should be addressed, at IMAZON. Email: jjg156@psu.edu 
(Phillips et al. 1998). Currently, human activities are leading to large scale, possibly long-term changes to the structure and species composition of forests in Amazonia (Laurance 1998). We are only beginning to understand the impacts of these changes on forest biomass but a likely scenario includes an increasingly important role being played by disturbance-adapted plant species (Laurance et al. 1997). Lianas, woody climbing plants that rely on other plants for structural support, represent a plant life form that is characteristically disturbance-adapted (Hegarty \& Caballé 1991, Putz 1984). Thus, lianas are likely to become increasingly more common in the future flora of Amazonia. To gauge the potential impact of increased liana abundance on forest biomass we need quantitative information on the relationship between liana abundance and total forest biomass in different forest types.

To date, the approaches that have been used to quantify the biomass of Amazonian forests can be divided into two classes. The first, destructive sampling, approach involves the harvesting and weighing of all the plants in relatively small sample plots (Klinge \& Herrara 1983, Klinge \& Rodrigues 1973). The second, volume-based, approach extrapolates biomass from the diameters of standing trees obtained from forest inventory data (Brown \& Lugo 1992). The main criticism of the former approach is that small sample plots are unlikely to provide a representative or random sample of the entire Amazonian forest. This problem could be exacerbated by investigator bias leading to the establishment of sample plots in especially pristine-looking forest patches where large trees may be overly abundant (Brown \& Lugo 1992). The main criticism of the latter is that its biomass estimates are based on inventories of trees $>25 \mathrm{~cm}$ dbh originally intended to provide timber volumes. In these biomass estimates, other components of forest composition (e.g. small diameter trees, palms, and lianas) are ignored as their contribution to total biomass is assumed to be negligible (Brown \& Lugo 1992).

In this study, destructive sampling was used to develop an allometric regression biomass equation to estimate the aboveground biomass of live lianas. This equation, used in conjunction with previously published equations to determine tree biomass, was then used to estimate the contributions of lianas and trees to the total biomass of forest patches differing in stature (i.e. height to the top of the canopy). Total stand-level biomass was estimated as the weighted average of the estimates for each forest stature class based on its relative abundance at the stand level.

\section{METHODS}

The site for this study was $20 \mathrm{~km}$ southeast of the town of Paragominas, Pará $\left(3^{\circ} \mathrm{S}, 47^{\circ} \mathrm{W}\right)$, in the eastern Brazilian Amazon. Mean annual rainfall in this region is $1700 \mathrm{~mm}$ and occurs mainly from December to May; during the remainder of the year, monthly rainfall averages $<100 \mathrm{~mm}$. The soils of the 
region are mostly oxisols and ultisols. Although the terrain of the region tends toward rolling, the study area was uniformly flat.

Sampling was conducted in a 130-ha plot of intact forest with no evidence of human disturbance that was surrounded by an extensive area of selectively logged forest. Using a system of parallel trails spaced at 25-m intervals, this area was mapped into four canopy height classes: gap (openings in the canopy of at least $25 \mathrm{~m}^{2}$ with the dominant vegetation $<3 \mathrm{~m}$ high), low (3-15 m canopy height), medium (15-25 m canopy height), and tall (> $25 \mathrm{~m}$ canopy height). To avoid classifying lone emergent trees as a patch of tall forest, at least two adjacent tall trees were necessary to define a patch of tall forest. Following mapping, stem size class and abundance of all trees and lianas was determined in ten, $100-\mathrm{m}^{2}$ sample plots located in each of low, medium and high forest classes. Gaps, defined as openings in the forest canopy with mean vegetation height $<3 \mathrm{~m}$, were not sampled. Plot locations were determined by randomly selecting $\mathrm{x}$ and $\mathrm{y}$ coordinates from a grid system located on the forest canopy map until 10 sites were located in each canopy height class. Within the sample plots, we measured the diameter of all lianas and trees $>2 \mathrm{~m}$ tall and determined the number of species (or morphospecies when species determination was not possible), of lianas present. Tree diameters were measured as dbh (1.3 $\mathrm{m}$ above the ground). Liana diameters were measured on each rooted stem at $1.3 \mathrm{~m}$ above the level of the ultimate rooting point. In this way we avoided making multiple measurements on stems that had partially fallen from the canopy and rerooted. Lianas were included if their ultimate point of rooting fell inside the plot and trees occurring on plot boundaries were included if they were more than half way inside the plot. The corresponding circular diameters of lianas with irregular stem shapes (e.g. species in the genus Bauhinia) were calculated from tracings of their cross-sectional areas. Hemiepiphytes, for example species of Areacea, were not included. Self-supporting plants $<2 \mathrm{~m}$ and $>5 \mathrm{~cm}$ tall were counted and classified as either tree or liana; plants which we were not able to identify were assumed to be trees.

The biomass (i.e. dry weight of all aboveground plant parts) present in each plot was calculated based on regression equations developed to relate biomass to dbh. We calculated tree fresh dry biomass using equations presented in Higuchi et al. (1997) for Amazonian tree species:

$$
\begin{aligned}
& \text { For trees }<20 \mathrm{~cm} \text { dbh: } \ln (\text { mass })=-1.754+2.665 \ln (\mathrm{dbh}) \\
& \text { For trees }>20 \mathrm{~cm} \text { dbh: } \ln (\text { mass })=-0.151+2.170 \ln (\mathrm{dbh})
\end{aligned}
$$

Dry biomass was calculated by multiplying fresh biomass by the mean dry mass: fresh mass ratio of 0.603 (Higuchi et al. 1997).

We developed an equation to relate liana diameter to biomass by harvesting and weighing 19 individual lianas with diameters ranging from 1.0 to $13.5 \mathrm{~cm}$ of 17 of the most common species at the site. A combination of tree felling and climbing trees to saw liana-bearing branches allowed us to obtain the harvested lianas in their entirety. All leaves were removed from harvested lianas and 
fresh weights of stems and leaves were determined in the field using hanging scales. Dry weights were calculated based on the ratio of dry weight to fresh weight determined for a subsample of stems and leaves of each liana harvested. In addition, 10 randomly selected leaves of each liana species were weighed and traced onto graph paper to determine leaf area-to-weight relationships. To allow us to compare relationships between leaf weight and dbh for trees and lianas, we also harvested and weighed 11 small trees in the same manner.

Statistical tests were performed using Minitab 11.21 (Minitab 1996). Differences among forest stature classes were analysed using ANOVA. When necessary, data were logarithmically transformed to improve homoscedasticity. Multiple comparisons among treatment means were conducted using Tukey's test at $\mathrm{P}=0.05$.

\section{RESULTS}

In 130 ha of surveyed forest, forest stature classes were found in the following relative proportions: gap phase $8 \%$; low stature $31 \%$; medium stature $44 \%$; and high stature $17 \%$. In total, we encountered 78 morphospecies of lianas in thirty 0.01-ha sample plots. There were significant differences among forest stature classes in the number of liana morphospecies present $(\mathrm{F}=37.04, \mathrm{df}=2,27 ; \mathrm{P}$ $<0.001)$. Low stature forest was the richest in liana species with an average of $21.7(\mathrm{SD}=4.0)$ species per plot compared to high stature forest with an average of 9.4 $(\mathrm{SD}=2.6)$. Similarly, the cumulative number of morphospecies encountered in a 0.1-ha sample was highest for low forest (66 species), and lowest for high forest (31 species). For each of the forest stature classes, however, cumulative species-area curves were still increasing after 0.1 ha had been sampled (data not shown). This indicated that total liana species diversity was undersampled in each case. The most common species, Bauhinia guianensis Aubl, was found in $93 \%$ of the plots. Other common species, occurring in $>60 \%$ of the total plots included: Adenocalima sp., Memora bracteaosa (D.C.) Bur. et. K. Schum, M. flavida (D.C.) Bur. et. K. Schum, M. schomburgkii (D.C.) Miers and Serjania tenuifolia Radlk. Nearly half the species (32 out of 78 in total) were rare, occurring in $<10 \%$ of the total plots. Of these rare species, only one was found in high stature forest.

On average, liana abundance was inversely correlated with forest stature. Low stature forest had five times the density and three times the basal area of climbing liana stems as high stature forest (Figures 1 and 2). The densities of tree stems $>2 \mathrm{~m}$ tall were nearly equal among forest stature classes (Figure 1). However, tree basal area was three times greater in high stature forest than in low (Figure 2). Forest stature classes also differed significantly in the percentage of self-supporting plants, $<2 \mathrm{~m}$ tall, that were lianas $(\mathrm{F}=5.96$, $\mathrm{df}=2,27 ; \mathrm{P}<0.01)$. In low stature plots, $33 \%(\mathrm{SD}=9.4)$ of these plants were lianas. This value dropped to $19 \%(\mathrm{SD}=7.9)$ in high stature forest and medium stature was intermediate with $25 \%(\mathrm{SD}=8.3)$. 


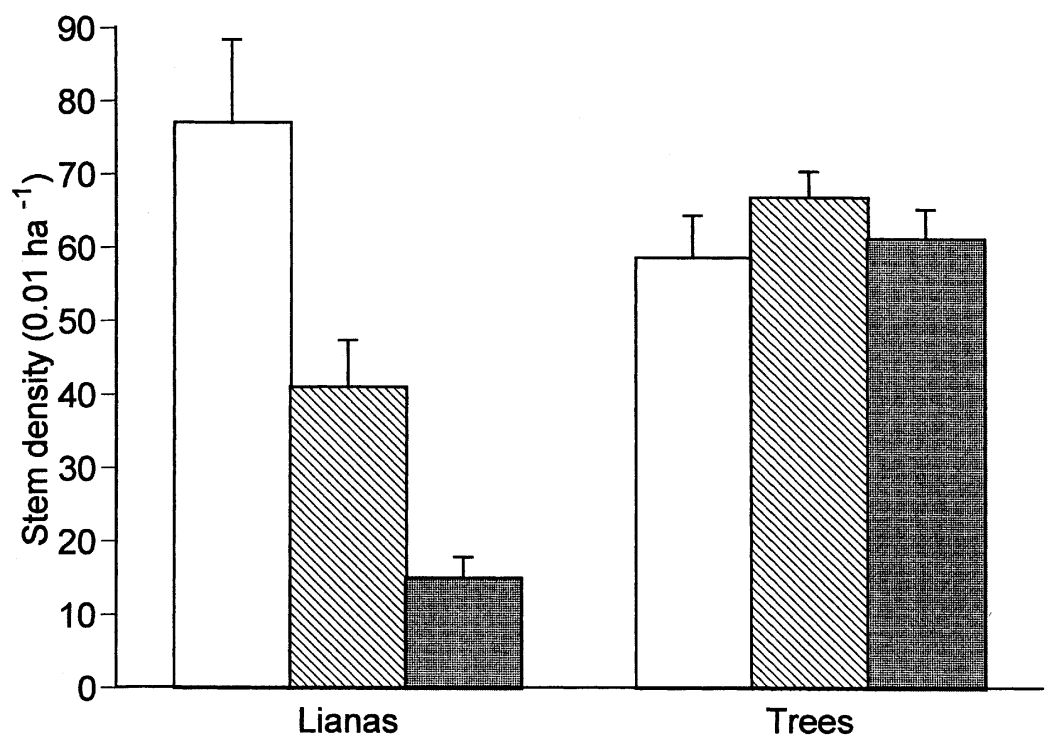

Figure 1. Mean stem density of climbing lianas and trees $>2 \mathrm{~m}$ tall for low (3-15 $\mathrm{m}$; open bars), medium (15-25 m; hatched bars), and high (>25 m; shaded bars) stature classes in forest near Paragominas, Pará, Brazil (error bars represent $1 \mathrm{SE} ; \mathrm{n}=10,0.01$-ha plots per forest stature class).

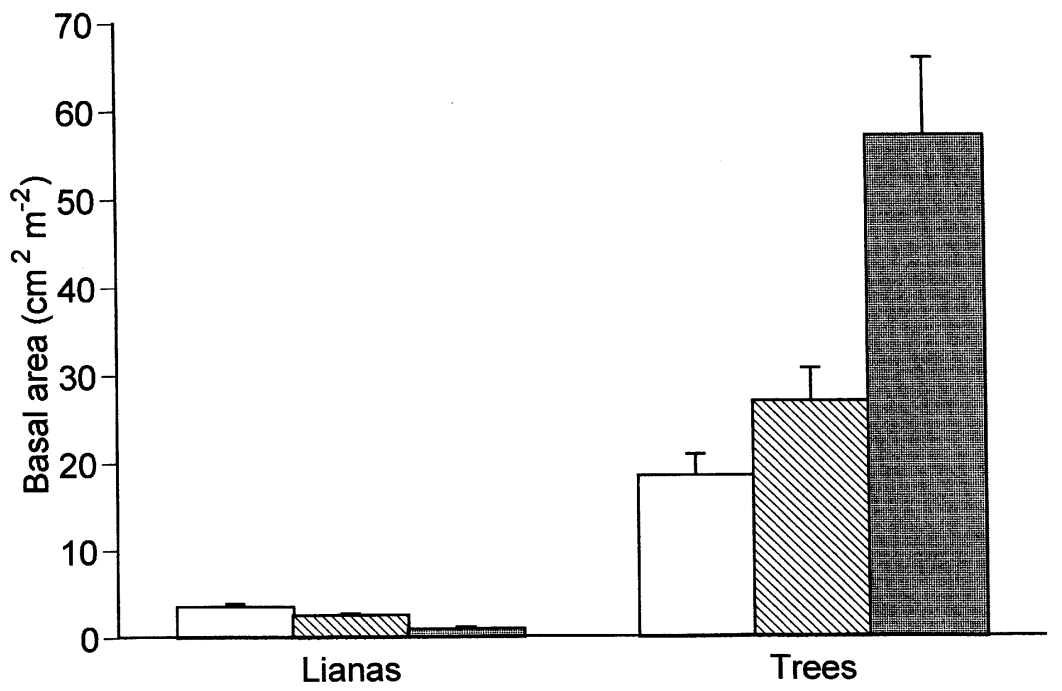

Figure 2. Mean basal area of climbing lianas and trees $>2 \mathrm{~m}$ tall for and low (3-15 $\mathrm{m}$; open bars), medium (15-25 m; hatched bars), and high (>25 m; shaded bars) stature classes in forest near Paragominas, Pará, Brazil (error bars represent $1 \mathrm{SE}$; error bars for lianas were too small to be visible; $\mathrm{n}=10,0.01$-ha plots per forest stature class). 


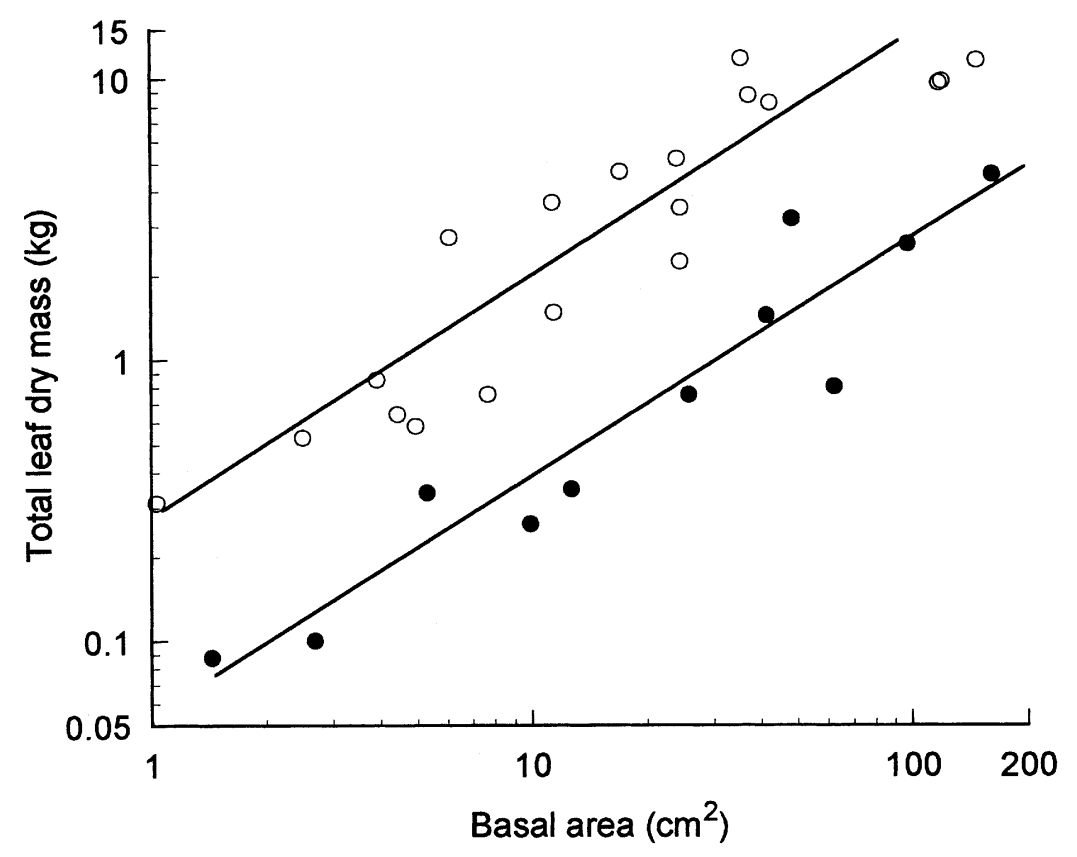

Figure 3. Relationships between basal area, at $1.3 \mathrm{~m}$ and total leaf dry mass for lianas (open circles; log (leaf mass) $=0.81 \log$ (basal area) $\left.-0.57, \mathrm{r}^{2}=0.84, \mathrm{n}=19\right)$, and trees (closed circles; $\log ($ leaf mass) $=0.84$ $\log$ (basal area) $-1.26, \mathrm{r}^{2}=0.89, \mathrm{n}=11$ ), harvested near Paragominas, Pará, Brazil.

A log-log plot provided the best fit (highest $r^{2}$ ) for the allometric regression used to relate total liana dry mass to dbh $(\log ($ mass $)=0.07+2.17 \log (\mathrm{dbh})$, $\left.r^{2}=0.95\right)$. Log-log plots also provided the best fits for the equations relating liana and tree basal areas to total leaf weights (Figure 3). The resulting regression equations for lianas and trees are parallel but differences in their intercepts result in greater estimated leaf weight for lianas for a given stem diameter. For example, for stems $1 \mathrm{~cm}$ in diameter, the predicted leaf weight for a liana is five times greater than for a tree; for $10 \mathrm{~cm}$ diameter stems, this difference drops slightly to a factor of four. Mean leaf mass-leaf area ratios did not differ significantly among liana $\left(85 \mathrm{~cm}^{2} \mathrm{~g}^{-1}, \mathrm{SD}=19.6, \mathrm{n}=16\right)$ and tree $\left(114 \mathrm{~cm}^{2} \mathrm{~g}^{-1}, \mathrm{SD}=46.8, \mathrm{n}=11\right)$ species $(\mathrm{t}=1.98, \mathrm{df}=12 ; \mathrm{P}>0.05)$.

There were significant differences among forest stature classes in total aboveground biomass, liana above-ground biomass, and liana leaf mass ( $\mathrm{F}=$ 10.23, 23.63 and 45.24, respectively, $\mathrm{df}=2,27 ; \mathrm{P}<0.001$ for each variable). Total biomass was three times higher in high stature forest than in low stature (Table 1). However, considering only lianas the inverse was true. In low stature forest lianas accounted for $30 \%$ of the above-ground live biomass whereas this value was only $3 \%$ in high stature forest. The greatest differences among forest stature classes were found for the weights of liana leaves present (Table 1). Low forest was found to contain over four times the weight of liana leaves as high stature. By multiplying the estimated mean values for liana leaf mass by 
Table 1. Aboveground biomass characteristics of forest in three canopy stature classes (high $>25 \mathrm{~m}$, medium 15-25 m, and low 3-15 m) and an area-weighted mean for 130 ha of never-logged forest near Paragominas, Pará, Brazil, $(\mathrm{n}=10,0.01$-ha plots per canopy height class; within a column, different superscripts indicate significant differences using Tukey's test $(\mathrm{P}=0.05)$.

\begin{tabular}{lccc}
\hline $\begin{array}{l}\text { Forest canopy } \\
\text { stature class }\end{array}$ & $\begin{array}{c}\text { Total aboveground } \\
\text { dry weight }\left(\mathrm{t} \mathrm{ha}^{-1}\right)\end{array}$ & $\begin{array}{c}\text { Liana aboveground dry } \\
\text { weight }\left(\mathrm{t} \mathrm{ha}^{-1}\right)\end{array}$ & $\begin{array}{c}\text { Liana leaf dry weight } \\
\left(\mathrm{t} \mathrm{ha}^{-1}\right)\end{array}$ \\
\hline High & $640(302)^{\mathrm{a}}$ & $18(14)^{\mathrm{a}}$ & $1.5(1.0)^{\mathrm{a}}$ \\
Medium & $305(154)^{\mathrm{b}}$ & $46(15)^{\mathrm{b}}$ & $4.0(1.2)^{\mathrm{b}}$ \\
Low & $209(89)^{\mathrm{b}}$ & $63(15)^{\mathrm{c}}$ & $6.2(1.1)^{\mathrm{c}}$ \\
Entire forest & 314 & 43 & 4.0 \\
\hline
\end{tabular}

the liana leaf mass-leaf area ratio, we calculated liana leaf area indices (LAI) of $1.3,3.4$, and $5.3 \mathrm{~m}^{2} \mathrm{~m}^{-2}$ for high, medium, and low stature forest, respectively.

\section{DISGUSSION}

We estimated stand-level biomass by weighting the contribution of each forest stature class to the mean value based on its relative abundance; gap phase forest was assumed to contain one-fourth the biomass of medium stature forest. This method resulted in an estimated total above-ground living biomass of 314 $\mathrm{t} \mathrm{ha}^{-1}$ for the forest as a whole of which, $43 \mathrm{t} \mathrm{ha}^{-1}(14 \%)$ were lianas. The contribution of lianas to total biomass rarely surpasses $5 \%$ in undisturbed forests (Hegarty \& Caballé 1991). In fact, the value we estimated is nearly two times higher than the $7.2 \%$ previously reported as the highest percentage contribution of lianas to total forest biomass (Bongers et al. 1985, cited in Hegarty \& Caballé 1991). This high value for lianas largely resulted from the high relative abundance of low stature forest where lianas accounted for a large proportion $(30 \%)$ of the total biomass.

Abundant lianas combined with low forest stature are usually interpreted as evidence of past forest disturbance (Hegarty \& Caballé 1991). In other regions of Amazonia, fire and the lingering effects of past human occupation have been proposed to explain the occurrence of liana-dominated forest patches (Balée \& Campbell 1990, Nelson 1994). Although there were no obvious signs of human disturbance in the forest we studied, naturally fallen logs were common in some, but not all, areas of low stature forest.

Given the high proportion of low stature forest in the area we studied, it may appear inconsistent that our stand-level estimate of total biomass, $314 \mathrm{t}$ $\mathrm{ha}^{-1}$, is $6-28 \%$ higher than the volume-based, basin-wide estimates for the biomass of dense forests of the Brazilian Amazon presented in Brown \& Lugo (1992). However, volume-based biomass estimates will underestimate total biomass when forest components other than large trees are common. Ignoring both lianas and small trees, $<10 \mathrm{~cm}$ dbh, would have resulted in a $19 \%$ underestimation of total aboveground biomass (14\% lianas and 5\% small trees). Indeed, when the estimate we obtained is reduced by $19 \%$ to $254 \mathrm{t} \mathrm{ha}^{-1}$ it is lower than the $298 \mathrm{t} \mathrm{ha}^{-1}$ volume-based estimate (Brown \& Lugo 1992). In an 
attempt to improve the accuracy of volume-based biomass estimates, Fearnside (1992) averaged the percentage contribution of lianas to total biomass from studies throughout the Amazon and suggested a correction factor of $4.3 \%$ to account for liana biomass. While this correction factor is slightly higher than the $3 \%$ value we calculated for the contribution of lianas to total biomass in high stature forest patches, it would still lead to an underestimate of biomass at the stand level in the forest we sampled.

Naturally occurring forest types with abundant lianas are not uncommon in Amazonia. In addition to the low stature forest patches in the study region, areas of forest characterized by low canopy height, low tree basal area and high abundance of lianas occur throughout eastern and southern Amazonia (Pires \& Prance 1985). These so-called liana forests cover $310000 \mathrm{~km}^{2}$ (c. 5\% of the area of the Amazon basin) and are concentrated in a region between the Tocantins and Tapajos rivers in the southern part of the Brazilian state of Para (IBGE 1997). There are no published biomass estimates for liana forest per se, but they fall into the general category of non-dense forests. Volumebased estimates of the biomass of non-dense forest are 30\% lower than those of dense forests (Fearnside 1992). The finding that lianas can contribute relatively high percentages to total aboveground biomass, suggests that volumebased estimates for non-dense forests could be particularly prone to underestimation if based solely on the volume of large trees.

The negative relationship between liana abundance and total aboveground biomass may also hold for anthropogenically disturbed forests. In central Amazonia, forest fragmentation has been followed by dramatic (9\%) declines in total biomass accompanied by increases in liana biomass from 5.4 to $7.9 \mathrm{t}$ ha $^{-1}$ (Laurance et al. 1997). At the global level, during the past three decades rising $\mathrm{CO}_{2}$ levels have been paralleled by increases in both tropical forest turnover rates and liana densities (Phillips \& Gentry 1994). If lianas are indeed favoured by the canopy gaps that are common in forests with high turnover rates (Putz 1984), then a negative relationship between liana abundance and total stand biomass could result in a positive feedback loop where rising $\mathrm{CO}_{2}$ levels and increasing liana abundance reinforce one another.

To date, most attempts to estimate the biomass of Amazonian forest have focused on relatively large trees ignoring or downplaying the contribution of other forest components such as lianas. While this approach may be justified in some situations, it is prone to underestimation in disturbed forests that are likely to become increasingly common throughout Amazonia. Perhaps an even greater risk in placing the focus of study solely on large trees is, however, that in ignoring other forest components, we will fail to discover important processes that influence forest biomass development. Lianas, for example, owing to stem allometry that allows them to support four to six times greater leaf weight than trees of equal stem areas, have the ability to generate high leaf area indices while maintaining relatively low total biomass (this study, Putz 
1983). If forest disturbance results in increased liana abundance, tree growth in these forests may be retarded by competition from lianas. This would result in a shift to a lower stature, lower biomass forest type. Understanding this dynamic will require further study of the impacts of various forest disturbances on liana abundance and an understanding of the persistence of liana dominated forest patches.

\section{AGKNOWLEDGEMENTS}

We would like to thank Metal and Miguel for helping with the fieldwork for this study. This paper benefited from the comments of Mark Schulze, Christopher Uhl and Roger Koide. Financial support for this study was provided by the World Wildlife Fund (WWF), Brazil and a grant from the PPG7'Programa de Pesquisa Dirigida' (MMA/MCT/FINEP) to the Instituto do Homen e Meio Ambiente da Amazônia (IMAZON).

\section{LITERATURE GITED}

BALÉE, W. \& CAMPBELL, D. G. 1990. Evidence for the successional status of liana forest (Xingu River Basin, Amazonia Brazil). Biotropica 22:36-47.

BONGERS, F. E., ENGELEN, D. \& KLINGE, H. 1985. Phytomass structure of natural plant communities on spodsols in southern Venezuela: the Bana Woodland. Vegetatio 63:13-34.

BROWN. S. \& LUGO, A. 1992. Aboveground biomass estimates for tropical moist forests of the Brazilian Amazon. Interciencia 17:8-18.

FEARNSIDE, P. M. 1992. Forest biomass in Brazilian Amazonia: comments on the estimate by Brown and Lugo. Interciencia 17:19-27.

HEGARTY, E. E. \& CABALLÉ, G. 1991. Distribution and abundance of vines in forest communities. Pp. 263-282 in Putz, F. E. \& Mooney, H. A. (eds). The biology of vines. Cambridge University Press, Cambridge.

HIGUCHI, N., SANTOS, J. d., RIBEIRO, R. J., MINETTE, L., \& BIOT, Y. 1997. Biomassa da parte aerea de vegetacao da floresta tropical umida de terra-firme da Amazonia Brasileira. Pp. 47-64 in Biomassa e nutrientes florestais. Projeto Bionte. INPA, Manaus.

IBGE. 1997. Diagnóstico Ambiental da Amazônia Legal. (CD-ROM using Vista-Map GIS, produced by IBGE/DGC/DERNA-DEGEO-DEGAR.)

KLINGE, H. \& HERRERA, R. 1983. Phytomass structure of natural plant communities on spodosols in southern Venezuela: the tall Amazon caatinga forest. Vegetatio 53:65-84.

KLINGE, H. \& RODRUGUES, W. A. 1973. Biomass estimation in a central Amazonian rain forest. Acta Cientifica Venezolana 24:225-237.

LAURANCE, W. F. 1998. A crisis in the making: responses of Amazonian forest to land use and climate change. Trends in Evolution and Ecology 13:411-415.

LAURANCE, W. F., LAURANCE, S. G., FERREIRA, L. V., MERONA, J. M. R.-d., GASCON, G. \& LOVEJOY, T. 1997. Biomass collapse in Amazonian forest fragments. Science 278:1117-1118.

MINITAB. 1996. Minitab Release 11.21. Minitab Inc., State College, PA, USA.

NELSON, B. W. 1994. Natural forest disturbance and change in the Brazilian Amazon. Remote Sensing Reviewes 10:105-125.

PHILLIPS, O. L. \& GENTRY, A. H. 1994. Increasing turnover through time in tropical forests. Science 263:954-958.

PHILLIPS, O. L., MALHI, Y., HIGUChI, N., LAURANCE, W. F., NUNEZ, P. V., VASQUEZ, R. M., LAURANCE, S. G., FERREIRA, L. V., STERN, M., BROWN, S. \& GRACE, J. 1998. Changes in the carbon balance of tropical forests: evidence from long-term plots. Science 282:439-442.

PIRES, J. M. \& PRANCE, G. T. 1985. The vegetation types of the Brazilian Amazon Pp. 109-146 in Prance, G. T. \& Lovejoy, T. E. (eds). Key environments Amazonia. Pergamon Press, Oxford.

PUTZ, F. E. 1983. Liana biomass and leaf area of a 'Tierra Firme' forest in the Rio Negro basin, Venezuela. Biotropica 15:185-189.

PUTZ, F. E. 1984. The natural history of lianas on Barro Colorado Island, Panama. Ecology 65:17131724. 